\title{
Productive Partnerships \\ Learning for Life
}

\author{
Margaret Spillman \\ Teacher-Librarian \\ Mackay West State School \\ Australia
}

\begin{abstract}
Our collaborative relationship with Mackay Libraries began informally when we undertook a work shadowing program with our Public Library counterparts. The professional discussions which followed, and an examination of the available literature on the topic of school and public library cooperation, indicated that we had much in common. More importantly, we realized that cooperation could be beneficial for our respective communities. Allan Bundy's excellent article, 'Essential Connections School and Public Libraries for Lifelong Learning' provided a wonderful historical perspective and also investigated attitudes of those involved in both library sectors. It was a challenging article and gave us the encouragement to believe that we could make a difference in our respective communities.
\end{abstract}

Thus was born Productive Partnerships - Public and School Libraries Promoting Lifelong Learning. Productive Partnerships ultimately came to embrace four main elements:

1. Work shadowing

2. GOAL (Grade Ones At the Library)

3. Library Monitor Program

4. School Website

NB. Year 7 Public Library Orientation has been added as a fifth element as of October 2005.

As early as 1966, it was noted in a 1966 report titled 'School and Children's Libraries in Australia' that "cooperation between public and school libraries was the best way of providing maximum service for children" (M Ninon, 2003 page 15). Clearly, Mackay West School Library and Mackay Libraries aim to serve a common group of young people and share common goals such as improved literacy. Perhaps, Maureen Ninon best summed up our philosophy when she said that 'commonality of purpose ensures that each library group can learn from the experiences of others and that a sharing of resources and effort will be mutually beneficial" (M Ninon, 2003 Pg 1). That has certainly been our experiences at Mackay West. We strongly believe that our Productive Partnership Program has indeed been very productive as evidenced by the outcomes achieved.

\section{The Process}

The development of Literacy, one of the key lifelong learning skills, is the core business of both School and Public Library Systems. Public and School Libraries provide the best opportunity for the development of networked learning communities and the acquisition of lifelong learning for all students. Our Productive Partnerships Program, through its four key elements, was able to deliver improved outcomes as a result.

1. Our Work Shadowing Program involved reciprocal weeklong visits for the Librarians and the Library Assistants from both Mackay West State School and the Mackay Libraries. The process and its outcomes were heavily publicized through the school's newsletter and on our website. The Program also received national prominence at the 2004 CBC/ASLA Conference. Anne Spelman from the Queensland State Library presented a paper called, In Visible Light: Illuminating Partnerships Across Libraries to Facilitate Lifelong Learning for Young People. She made a special reference to the Queensland scene by discussing the Work Shadowing Program, which was run between our Libraries. She also noted that this was one way to understand and appreciate each other's role. 
2. In 2002, Library Staff at Mackay West School decided to implement a Library Monitor Program. A commitment was made to skilling Year 7 students who were prepared to volunteer their time and effort as administration support in the Library. Twenty Year 7 students are selected each year and they are presented with their badges at the school's annual 'Induction Ceremony'. The Library Monitor Program has five main components:

- Providing support for Library Administration

- Increasing ICT Skills

- Providing alternative forms of leadership

- Developing personal skills

- Forming a strategic alliance with the Mackay City Library

This Program is now well entrenched in the school culture and is recognised for its contribution to the skill development of young people. It also has strong support from the parent body of the school as evidenced by the testimonials in Appendix 30.

3. GOAL (Grade Ones at the Library) actively encourages every Year One student to join their local public library. The program is heavily advertised through the school newsletter. Application forms are sent home with every Year One student. Returned forms are sent to Mackay Libraries for processing. The cycle is completed when the Young People's Librarian visits each Year 1 class to hand out the membership cards and engage in a story telling session. Year 1 students were enthralled by the complex pop-up picture books which Mackay Libraries staff shared with them. The interactive story time involving hand held puppets was also well received.

4. The School Website is used to inform, to educate, to publicise and to promote. It is curriculum based and also provides very comprehensive documentation of all aspects of the Productive Partnerships Program. There are numerous photographs of all elements of Productive Partnerships for the school community to view. By publicising our work on the web we can 'model' our system for other schools to use and adapt.

\section{Outcomes}

1. Work Shadowing Program at Mackay West State School has:

\section{Forged closer links between School and Public Libraries (App 2, Testimonial G)}

Jointly promoted each other's services and resources by gaining a greater awareness of same.

Resulted in a network arrangement which shares basic information - the benefits flow on to other schools in the district.

Developed greater awareness of each other's job description/role.(App 4, Fig 4)

Enabled Mackay High to undertake Work Shadowing based on our model (App 2, Testimonial F)

Resulted in Mackay West School Library acting as a consultant on a wide range of Council Library issues:

1. Purchasing new resources

2. Awareness of age appropriateness/suitability/reading levels/interest level of library material

3. New shelf labelling in Junior Non-Fiction section of the City Library

4. Separation at Gordon White Library of Junior Non-Fiction resources from adult section

2. Library Monitor Program at Mackay West State School: 
$>$ Provides an alternative form of leadership and contribution to the School Community for upper school students with approximately $40 \%$ of Year 6 students now applying for the Library Monitor Program.(App.1, Fig 2 )

Recognizes the important volunteer and leadership roles provided by Library Monitors by the presentation of badges by the Young People's Librarian, at the ceremony for School Leaders.

$>$ Provides experiences for all students across the learning spectrum due to the inclusive nature of the program.(App 2, Testimonial A)

Develops and improves students' ICT skills. (App 2, Testimonial D)

$>$ Improves self-esteem, social skills and promotes self-organization.( App 2,Testimonial B)

$>$ Provides awareness of shared common elements such as improved Literacy level and the connectedness of School and Public Libraries.(App 2, Fig 7)

$>$ Encourages active citizenship through a vision of how volunteer services operate both at school and in the wider community through "Friends of the Library". ( App 2, Testimonial C)

Formalizes a structure which continues regular reciprocal visits between the two Libraries. The Library Monitors visit two branches of the Mackay Libraries each year and the Young People's Librarian conducts regular workshops for the Library Monitors at Mackay West State School

\section{GOAL (Grade Ones at the Library) at Mackay West State School:}

Encourages library membership at Council Libraries amongst Year Ones. (App 2, Fig 6)

Increases borrowing of resources, especially that of Fiction which assists with Literacy Skills.

$>$ Promotes awareness of Council Services, particularly in the area of reading levels for Junior Fiction.

Increases familiarity with Public Library Staff through story time sessions by Young People's Librarian at Mackay West School.

$>$ Educates/Informs parent community about school and public library services through school newsletters.(App 3, Figure3)

Identifies the Public Library as an extension of the School Library to Year One parents, caregivers and students.

Facilitates a flow-on effect as students from other year levels as parents seek membership.

> Uses Mackay West School's GOAL Program as an example of 'Best Practice' as Mackay Libraries seek to implement this idea in other District Primary Schools. (App 3, Fig 4)

> Uses a CD/Master Folder created by Mackay West School Library Staff to provide templates e.g. letters to parents, teachers and principals to help facilitate implementation of the GOAL Program in other District Schools.

\section{Mackay West State School’s Website www.mackwestss.eq.edu.au}

$>$ Documents all four elements of the Productive Partnership program making them available on our School Website for general access. We have received enquiries about our program from all over Australia.(App 2, Testimonial $H$ and App 1, Fig 1))

\section{Publishes criteria sheets for assessment items to assist Public Library Staff with inquiries} (85\% of which relate to assignment work)

$>$ Organizes OBE (Outcomes Based Education) units and assessment items into year levels and school terms to provide easy access by students, teachers and parents.

> Communicates to parent community by providing access to newsletters/ assessment items, suitable websites and a broad range of useful information (App 2, Testimonial I) 
Provides extensive/comprehensive range of relevant/safe websites.(App. 2, Testimonial I)

Meets "Best Practice" criteria and is in frequent use by other schools.(App 2, Testimonial E)

Displays user-friendly organization of web links to facilitate easy use by students for educational and recreational purposes.

Supports the learning, teaching and curriculum area of the Information and Communication Technology (ICT) agreement (App 4, Fig 3)

\section{Sustainability and Transferability}

The Productive Partnerships Program could be implemented as a whole or alternatively parts of it because our Program is so well documented on our school website. St. Joseph's Catholic School in Mundingburra, Townsville, has used our Library Monitor Program as a basis to build their own Program (App 3, Testimonial H).

This year, we initiated the Year 7 Orientation Program with Mackay Libraries and their new Young People's Librarian, Wendy Batho. Winnings from the IASL/Softlink Excellence Award enabled us to provide a free excursion for students. Positive feedback affirmed the value of taking students to their public library. Because all elements of Productive Partnerships are based firmly on processes, not personnel alone; our program is completely adaptable, sustainable and transferable. 


\section{Productive Partnerships Presentation at}

\section{School Library Association of Queensland Biennial Conference 2004}

EVALUATION by Workshop Participants

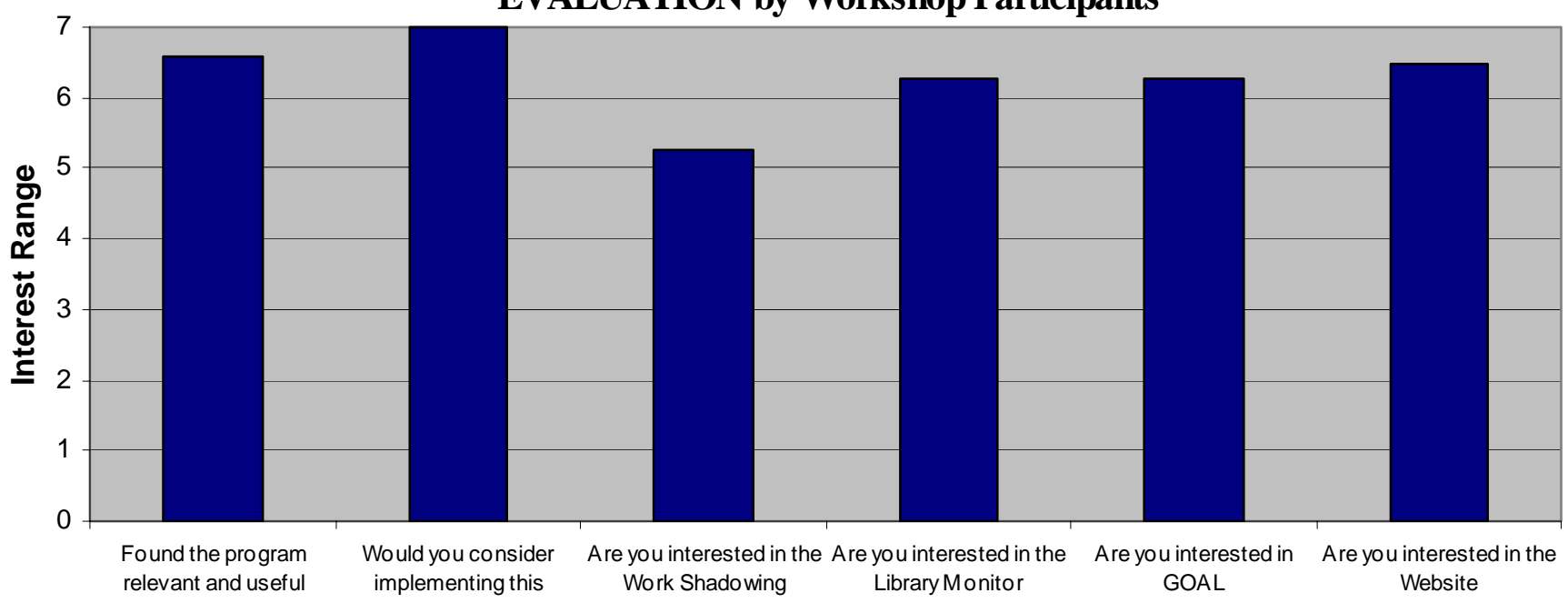

Figure 1: In 2004, Margaret Spillman (Teacher-Librarian), Lorraine Todd (Library Assistant) and Claire Grandcourt (Young People's Librarian, Mackay Libraries) presented the Productive Partnerships Program at the SLAQ Conference. Nineteen Teacher-Librarians attended the workshop and ten evaluations were completed with interest in the Program measured as follows: 1 - Not at all, 4 - OK, 7 - A Great Deal.

\section{Comments:}

$>$ Great Work! Something to aim at.

$>$ What a Team!! Positive Actions.

$>$ Congratulations, you are all inspirational. Thank you for sharing and for your enthusiasm.

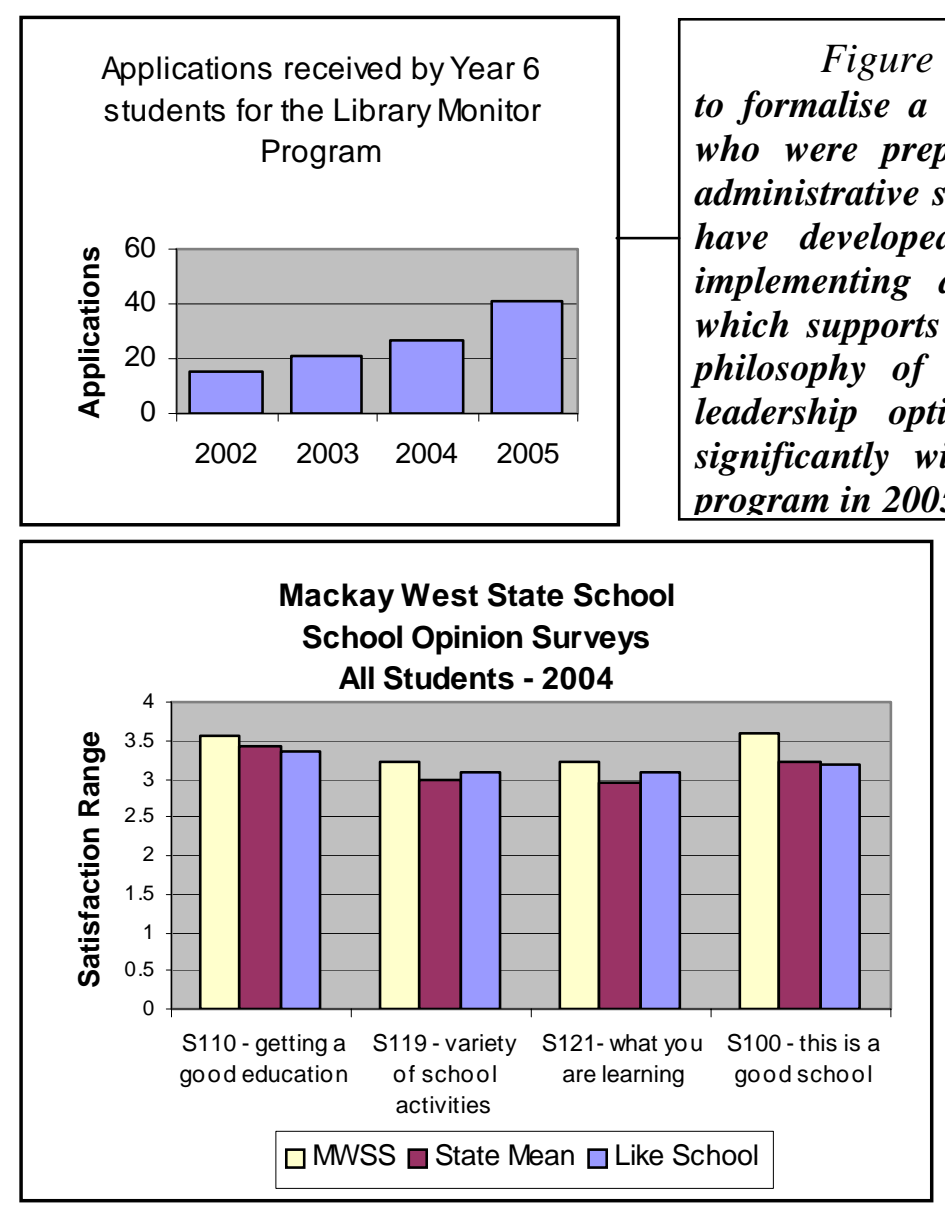

Figure 3: Mackay West State School's Mean is measurably higher than the State and Like Schools Benchmarks

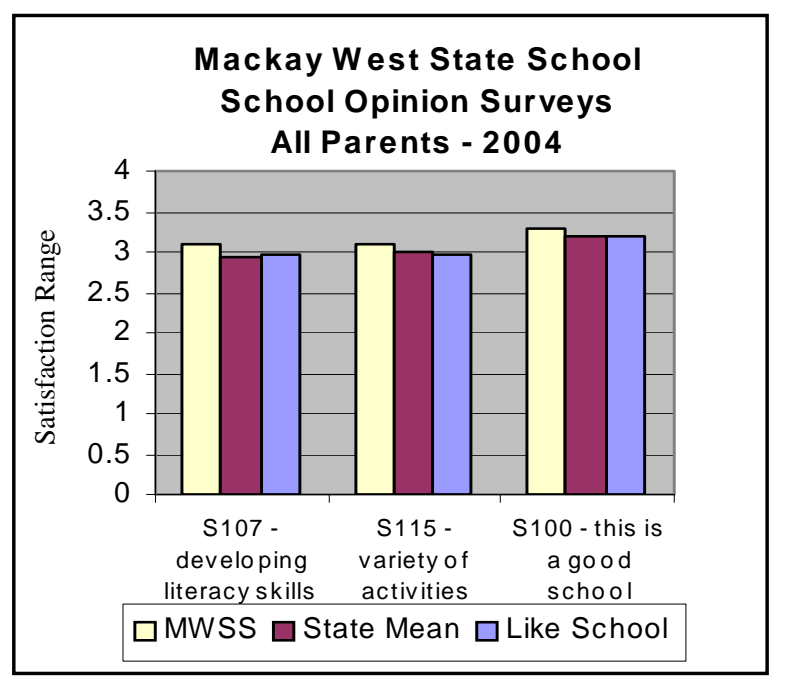

Figure 4: Mackay West State School's Mean is higher than the State and Like Schools Benchmarks 


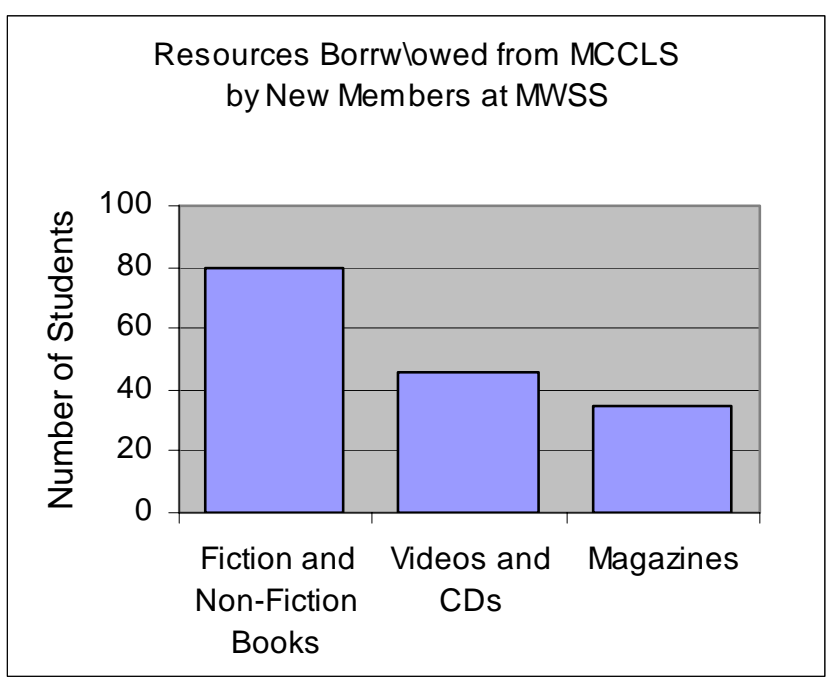

Figure 5:

A survey was conducted of 100 MWSS students who gained membership of the MCCLS through the Program. 87\% of new members visited the MCCLS. $80 \%$ of Resources borrowed were Fiction and NonFiction, which has clear implications for
MWSS Students

who are members of the Council Library

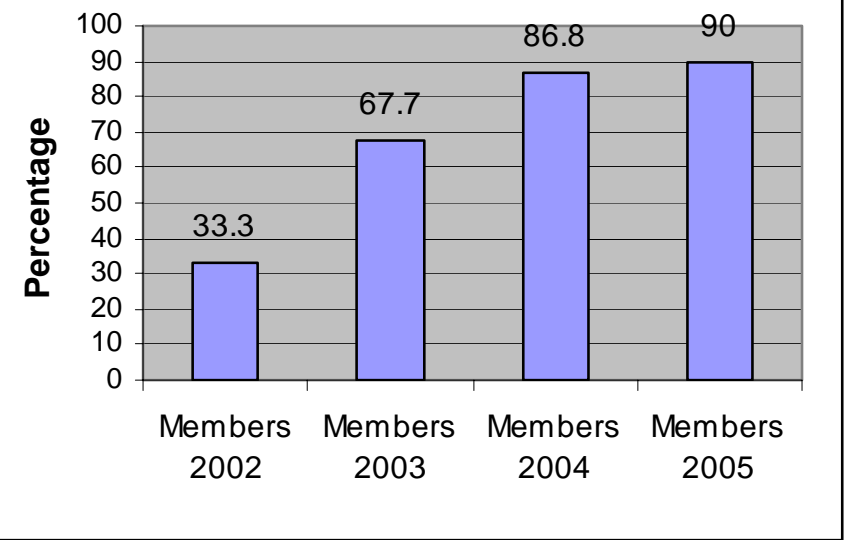

Figure 6:

Since developing our Productive Partnership Program, Mackay West State School student membership of the Mackay City Council Library Service has grown to approximately $90 \%$.

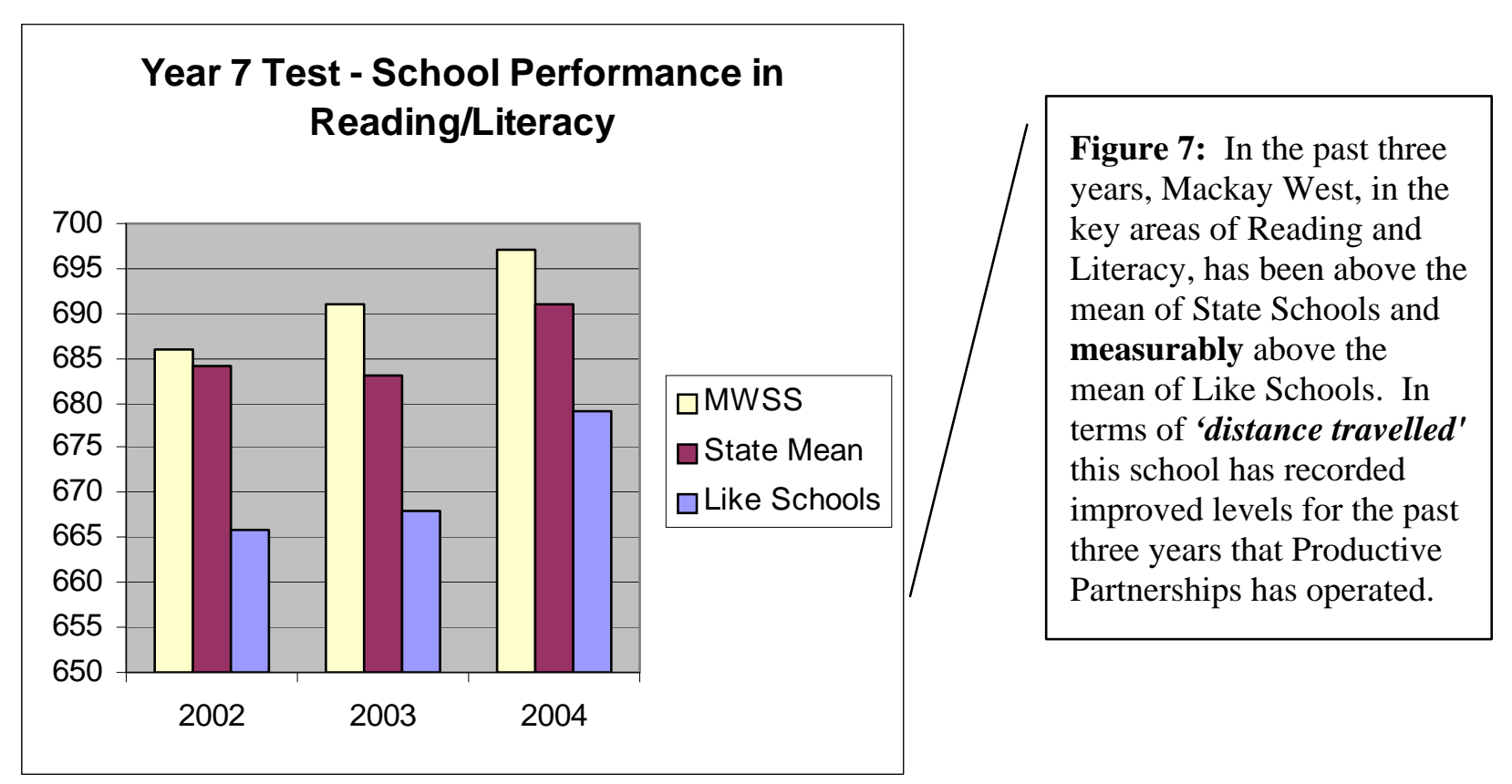

Figure 8: In the past 12 months, the number of students identified as being in the bottom $15 \%$ of Literacy has been slashed by $50 \%$ at MWSS. Our level of $8.4 \%$ is measurably below the state mean of $17.5 \%$ and Like Schools $24.5 \%$
Year 5 Test - School Performance

Proportion of students identified as being in the bottom 15\% Literacy

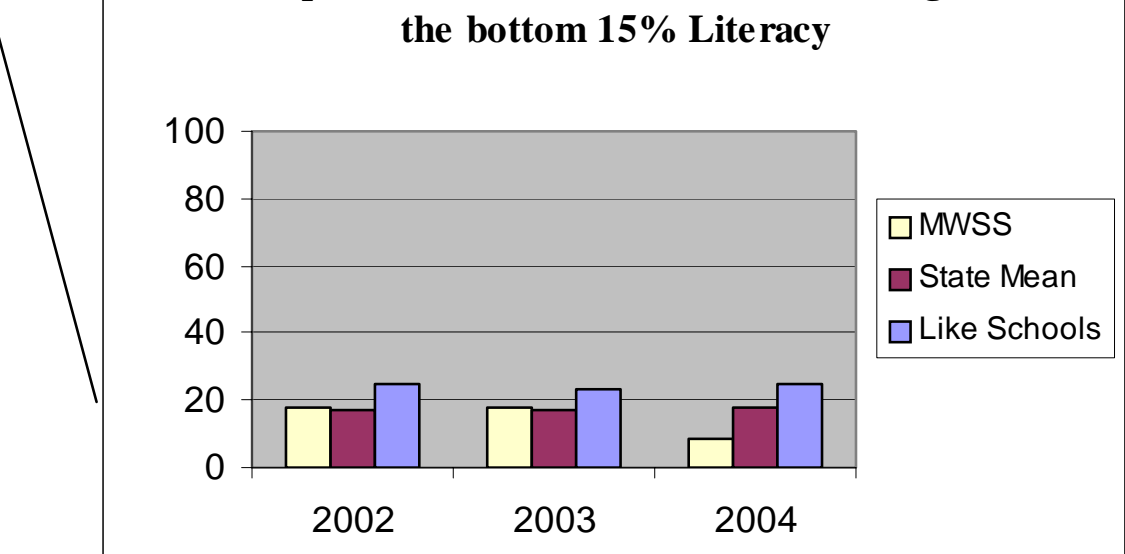




\section{A) Nola Bennett,Mother of Andrew, Library Monitor 2003}

My son, Andrew, was a Library Monitor in 2003. Andrew was one of two students from the Special Education Unit. What he especially enjoyed was the sense of achievement he gained. Andrew learnt new computer and social skills by working with different people and assisting in the Library. My son felt that he was more a part of everything through his clearly designated role as a Library Monitor. As a parent, I love what this program offers.

\section{B) Leanne Simpson}

\section{Mother of Bonnie, Library Monitor 2004}

My daughter Bonnie was a Library Monitor at Mackay West in 2004. I believe that the Library Monitor Program was wonderful for Bonnie's personal and social development. It gave her a clear sense of belongingness, which is also important in the early years of adolescence. The Program offered an alternative form of leadership at the Middle School level. Bonnie is now at High school and has confidence as well as good social and personal skills. I do truly believe that her participation in the Library Monitor Program assisted her greatly.

\section{C) Claire Grandcourt- Young peoples' librarian, Mackay Libraries}

The library monitor program has had an enormous positive impact on senior students and the school community as a whole eg. diversifying school leadership, encouraging active citizenship, learning practical skills, the ability to share knowledge with peers, working in a professional environment and encouraging student ownership of the Library. Mackay Libraries has also benefited from the principles taught by the Program.

\section{D) Chris Dunn - Library Monitor 2002}

I thought I'd be sitting behind a desk all day. When I started the Program I was surprised at how busy I was. At first I didn't have a lot of computer skills, but I have learnt a lot this year. What I have learnt at school has also helped me locate books at the City Library. The program has given me lots of confidence in computers as well as speaking.

\section{E) Lesley Pecchiar, Principal Moranbah SS (Oct 04)}

I just wanted to express my sheer admiration I have for the MWSS website. Our school is currently re constructing our web page for our school and have been viewing many via the Cool Schools websites and we are very impressed with Mackay West's.
F) Laurel Magill, Teacher-Librarian, Mackay State High School

In 2005, the Library Staff are participating in a Work Shadowing Program based upon the model used by Mackay West. We had heard of the many wonderful benefits, which had resulted from their experience, and we wanted to see if we could replicate some of these in a high school situation. The information on their website was helpful and informative to us.

\section{G) Denise O’Connor, Public Library Service, State Library of Queensland}

Good to hear from you and to find out about your partnership with Claire Grandcourt and the Mackay Public Library. I have had a look at your website and it is very informative and gave me a good understanding of and background to the program. It is obvious from the testimonials of staff and feedback from students that the work shadowing partnership and library monitor program are benefiting all those involved as well as the community at large. It is a really great program.

\section{H) Lisa Ganter, Teacher- Librarian, St. Joseph's, Townsville.}

I saw your work at Mackay West State School on the Internet and was so impressed with what you are doing in your school. I am writing to ask your permission to use some of your amazing work in your Library Monitors' program. I have just started working as a TeacherLibrarian this year and would really like to work with children in a similar meaningful way in preference to having them just be "book box tidiers."

I started searching the internet and of everything I saw, your program was just outstanding. Of course, not everything in our school situation will mirror yours, but I was hoping you mightn't mind if I used some of your content as a base from which to start, and also some of the forms you have already developed - e.g. Monitor's Quiz and Survey.

I love your idea of taking the children to the City Library. I also work at Townsville Library Service and can see many benefits and opportunities of doing this. I will look forward to hearing from you Margaret. Thanks for publishing your wonderful work on the web.

\section{I) Lashona Petersen-Parent}

I have just discovered your wonderful website. Your Cyberville site is incredible. What a wonderful tool for our children to access. Keep up your great work! 


\section{References}

Bundy, A, September, 2002 Essential connections, schools, parents and public libraries, University of South Australia Library, viewed Sept 11, 2002

http://www.library.unisa.edu.au/papers/essconnect.htm

Nimon, M, 2003, Connecting Challenges: Issues for Teacher and Children's Librarians, Series Number 11, Auslib, Adelaide.

\section{Bibliography}

Browning, P, 2005,Facilitating Partnering: Change Integration Project, CYS/ALIA Conference, Powering our Partnerships-Learning through Libraries, Brisbane

Dyer, J, 2001, Library volunteer and service providers; a protype for creating a "grace space”, ALIA Groups, viewed Sept 2, 2002

http://alia.org.au/groups/libtnat/conferences/2001/papersa/12.dyer.html

Gardiner, W, 2005, A Study of the Demographics of Student Use of Public Library Facilities in Mackay, Report to Mackay Libraries.

Guidelines for Using Volunteers in Libraries, 2002, Connecticut State Library, viewed May 25, 2002;

http://www.cslib.org/volguide.htm

Hartzell, G 1997, The Invisible School Librarian: Why Other Educators Are Blind to Your Value (part 2)

School Library journal, viewed July 24, 2002

http://www.slj.com/articles/articles/

Hofto, J, 1999, Inventing our future with Partnerships, ACCESS, Vol 13, No 4, pp24-26

Jones, J, 2004, Come Together, viewed Jan 2004

http://www.schoollibraryjournal.com/article/CA386728.html

Library Monitor Training is Initiated, April 2002, The Daily Mercury, Mackay

Lonsdale, M, 2003, Impact of School Libraries on Student Achievement: a Review of the Research, ACER, Camberwell, Vic

Oberg, D, 2001, Research indicating school libraries improve student achievement, ACCESS, Vol 15, No3, pp11-14

Pilot participant a technology whiz, Sept. 2004, Ed Views, Brisbane

Program Gets Honourable Mention, Oct. 2004, The Midweek, Mackay

Robinson, J, 2004, School Libraries: Impact on Student Achievement, Scis connections, Issue48, 2004, pp1-5

Sexton,D, Oct. 2004, Libraries Lend a Hand, The Daily Mercury, Pg2, Mackay

Six Guiding Principles, 2004, ALIA

Spelman, A and Kelly, p, 2003, Hobart, In Visible light: Illuminating Partnerships Across Libraries to Facilitate Lifelong Learning for Young people, Joint Conference of the CBC and ASLA, Oct 2003

Spelman, A, 2002, Essential connections: Connecting School and Public Library Professionals, Scis connection, Issue 43, pp8-11

21 st Century Literacy, ALA, 2001, Viewed Feb 2, 2005

http://ala.org/work.literacybrochure.html 


\section{Author Note:}

Margaret Spillman is Teacher-librarian at Mackay West State School, Queensland, Australia and has presented Productive Partnerships at both local and state school and public library conferences.

Productive Partnerships won the IASL Softlink Excellence Award for 2005. It has also been included in the 2006 ASLA (Australian School Library Association) online Visions of Learning Conference in the section called Powerful Practices. Margaret has been a Teacher-Librarian for more than 10 years. Her major interest lies in promoting the educational benefits, especially Literacy, which stem from collaborative relationships with public libraries.

\section{Statement of Originality}

Research papers

This statement certifies that the following paper is based upon original research undertaken by the author and that the paper was conceived and written by the author alone. All information and ideas from others is referenced.

Author Signature

Name

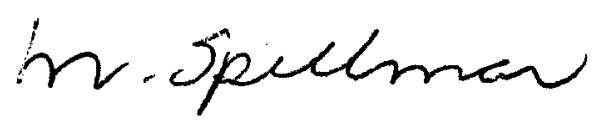

Margaret

Spillman

Professional papers and workshops

This statement certifies that the following paper was conceived and written by the author alone. All information and ideas and others are referenced.

Author Signature

Name

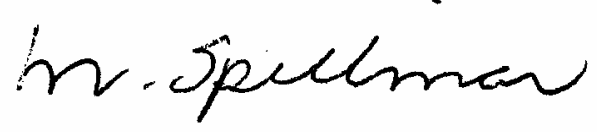

Spillman 
Reproduced with permission of the copyright owner. Further reproduction prohibited without permission. 